\title{
ATENÇÃO PRIMÁRIA E DOENÇA FALCIFORME: uma revisão sobre o papel do gestor
}

\author{
PRIMARY HEALTH CARE AND SICKLE CELL DISEASE: \\ a review about manager's role
}

\begin{abstract}
Lívia Gelain Castilhos', Josiane Bizzi Schlemmer Braun², Suzinara Beatriz Soares de Lima³
\end{abstract}
\section{RESUMO}

O objetivo deste estudo foi realizar na literatura uma revisão sistemática de artigos científicos que mencionem a respeito do papel do gestor na atenção primária à saúde e na garantia da adesão ao tratamento dos pacientes portadores de anemia falciforme. Foi realizada busca em diferentes bases eletrônicas de dados (Literatura Latino-Americana e do Caribe em Ciências da Saúde, Medical Literature Analysis and Retrieval System Online, US National Library of Medicine National Institutes of Health, e no Scientific Electronic Library Online) no período de maio de 2004 a maio de 2014, utilizando os seguintes descritores: gestão em saúde, atenção primária à saúde, anemia falciforme e terapêutica. Os usuários do sistema reportam um atendimento inadequado por parte dos profissionais da saúde devido a desinformação sobre a doença, assim como a falta de acesso aos medicamentos essenciais nas unidades básicas de saúde. Uma maior ênfase por parte dos gestores sobre a doença falciforme deve ser dada na educação dos profissionais de saúde atuantes nas unidades básicas. Embora posteriormente o usuário necessite de ambulatórios de atenção secundária, tudo deve estar atrelado à atenção primária, a qual deve coordenar o fluxo e acompanhar o usuário.

Descritores: Gestão em Saúde; Atenção Primária à Saúde; Anemia Falciforme; Terapêutica.

\section{ABSTRACT}

The aim of this study was to conduct a systematic literature review of scientific articles that mention about the manager's role in primary health care and ensuring adherence to treatment of patients with sickle cell anemia. The search was performed in different electronic databases (Latin American and Caribbean Health Sciences, Medical Literature Analysis and Retrieval System Online, US National Library of Medicine National Institutes of Health, and the Scientific Electronic Library Online) within May 2004 to May 2014, using the following descriptors: health management, primary health care, sickle cell disease and therapy. System users reported an inappropriate care by health professionals due to misinformation about the disease, as well as the lack of access to essential medicines in primary health care units. A greater emphasis by managers about the sickle cell disease should be given to the education of health professionals working in basic units. Although later the patients need secondary care, everything should be linked to primary care, which must coordinate the flow and follow the user.

Descriptors: Health Management; Primary Health Care; Anemia; Sickle Cell; Therapeutics.
${ }^{1}$ Doutora em Ciências

Farmacêuticas pela Universidade Federal de Santa Maria (UFSM), Santa Maria, RS, Brasil.
${ }^{2}$ Mestre em Bioquímica
Toxicológica pela Universidade Federal de Santa Maria (UFSM), Santa Maria, RS, Brasil.
${ }^{3}$ Doutora em Enfermagem pela Universidade Federal do Rio de Janeiro (UFRJ), Rio de Janeiro, RJ, Brasil. 


\section{Introdução}

As hemoglobinopatias constituem uma das principais e mais frequentes doenças genéticas que acometem os seres humanos e, dentre elas, a anemia falciforme (AF) é a doença hereditária mais prevalente no Brasil. A mutação genética, responsável por esta patologia, surgiu há muitos séculos na África e, por isso, a doença é muito presente em nosso país, cuja população tem em sua base de constituição os povos africanos ${ }^{1,2}$.

De acordo com os dados do Programa Nacional de Triagem Neonatal (PNTN), no Brasil, nascem cerca de 3.500 crianças por ano com doença falciforme (DF) ou 1/1.000 nascidos vivos e 200 mil portadores do traço falciforme, com tendência a atingir uma parcela cada vez mais significativa da população, devido ao alto grau de miscigenação em nosso país. A incidência de nascidos vivos diagnosticados com a doença falciforme no estado do Rio Grande do Sul é de 1:11.000, enquanto que a incidência de nascidos vivos diagnosticados com traço falciforme é de 1:65 ${ }^{3}$.

$O$ termo doença falciforme engloba um grupo de anemias hemolíticas hereditárias que têm em comum a presença de hemoglobina "S" (HbS) nos eritrócitos. A HbS é uma variante da hemoglobina normal, a hemoglobina " $A$ " (HbA), e originada devido a uma mutação genética que afeta uma das bases nitrogenadas do ácido desoxirribonucleico que compõe o gene que sintetiza a globina beta ${ }^{4}$.

A anemia falciforme é considerada uma doença de elevada prevalência e grande relevância no contexto da saúde pública no Brasil. Seu diagnóstico precoce possibilita o início da educação em saúde para a família e a introdução da profilaxia e terapêutica necessárias, resultando em melhor sobrevida e qualidade de vida dos portadores 5 .

A atenção básica, ou também conhecida como atenção primária, caracteriza-se por ações individuais e coletivas de promoção e proteção à saúde, de prevenção de doenças, de diagnóstico, de tratamento, de reabilitação e de manutenção da saúde . $^{2}$

A compreensão perante as famílias destes pacientes é necessária em relação a necessidade de intervenção precoce com medicações, nutrição adequada, suplementação com ácido fólico e elevada ingestão hídrica, as quais são medidas relativamente simples que podem ser orientadas em unidades básicas de saúde e que possuem impacto na história natural da doença $a^{7,8}$.

Segundo a Organização Mundial de Saúde (OMS), na maioria dos países onde a anemia falciforme é problema de saúde pública, seu manejo permanece inadequado devido à inexistência de programas nacionais de controle e de práticas sistemáticas de rastreamento populacional ${ }^{7}$. 0 manejo dos pacientes com anemia falciforme deve basear-se na atenção primária em saúde, com ênfase em programas simples e de baixa tecnologia em equipamentos que atinjam grande proporção da comunidade, tais como educação em saúde, detecção de risco genético na comunidade com base na história familiar, aconselhamento genético e imunizações ${ }^{8}$.

Por se tratar de uma doença crônica, é necessário que o paciente com AF tenha um acompanhamento contínuo, devendo ser considerada a oferta de assistência qualificada pelos serviços de atenção primária à saúde. Por conseguinte, o objetivo deste estudo foi realizar na literatura uma revisão sistemática de artigos científicos que mencionem a respeito do papel do gestor na atenção primária à saúde e na garantia da adesão ao tratamento dos pacientes portadores de anemia falciforme.

\section{Metodologia}

Foi realizada uma revisão sistemática de artigos científicos em diferentes bases eletrônicas de dados (Literatura Latino-Americana e do Caribe em Ciências da Saúde, Medical Literature Analysis and Retrieval System Online, US National Library of Medicine National Institutes of Health, e no Scientific Electronic Library Online) no período de maio de 2004 a maio de 2014, utilizando os seguintes descritores: gestão em saúde, atenção primária à saúde, anemia falciforme e terapêutica. Foram critérios de inclusão no estudo: artigos indexados nos banco de dados com as palavras-chaves elencados acima; artigos publicados em periódicos nacionais no período de maio/2004 a maio/2014, artigos disponíveis gratuitamente e publicados em português. 0 número total de artigos encontrados nas bases de dados foram de 52 , portanto 7 artigos pagos foram descartados. Dentre a leitura dos 45 restantes, 40 artigos foram utilizados para a presente revisão, pois 5 deles se repetiam em mais de uma das bases pesquisadas. As análises dos artigos foram transcritas em duas categorias, a primeira enfatizando a atenção primária à saúde na doença falciforme e a segunda destacando 0 papel do gestor neste seguimento em saúde. 


\section{Resultados e Discussão}

\section{Atenção primária à saúde na doença falciforme}

A anemia falciforme é uma doença genética em que as hemácias falciformes são mais rígidas e tem dificuldades para passar pelos vasos sanguíneos mais finos, causando assim a sua obstrução e provocando o que chamamos de micro-infartos. Estes micro-infartos locais provocam crises de dor e comprometimento progressivo de diversos órgãos ${ }^{9}$. Sem flexibilidade para passar por capilares pequenos, as hemácias vão se acumulando e obstruindo a circulação sanguinea, 0 que implica, por conseguinte, na dificuldade da oferta do oxigênio aos tecidos e órgãos dos sistemas do corpo ${ }^{10}$.

Dentre os sintomas e as consequências causados por esta doença, podemos citar a anemia, a dactilite falcêmica (síndrome mão-pé), crises dolorosas, infecção e febre, icterícia, crise de sequestro esplênico (retenção de sangue) no baço, úlceras de pernas, priapismo (ereção dolorosa e prolongada do pênis) e acidente vascular cerebral (AVC) ${ }^{9}$. Portanto, a população com AF apresenta baixa expectativa de vida, geralmente estimada em 42 a 53 anos para os homens e 48 a 58 anos para as mulheres ${ }^{11}$.

A anemia falciforme até 1997 não estava incluída nos processos de formulação das políticas públicas de saúde. Apesar da alta incidência na população negra esta doença não era priorizada pelas ações implementadas pelo Estado, consequentemente poucos foram os estudos produzidos sobre o tema. A anemia falciforme esteve em evidência a partir de meados dos anos 90 ao ser considerada uma doença genética específica da população negra e, com isso, deu legitimidade à adoção de políticas de ação afirmativa de recorte racial no campo da saúde pública brasileira ${ }^{12}$.

Por apresentar prevalência elevada no Brasil, o diagnóstico da AF passou a ser realizado pelo teste de triagem neonatal ou teste do pezinho, desde junho de 2001, com a criação do Programa Nacional de Triagem Neonatal ${ }^{13,14}$. 0 diagnóstico, assim como o tratamento precoce, aumenta consideravelmente a sobrevida e a qualidade de vida desses indivíduos, atenuando suas sequelas e complicações clínicas ${ }^{14}$.

A publicação da Política de Atenção Integral às pessoas com doença falciforme e outras hemoglobinopatias colocou um desafio para a coordenação geral da Política Nacional de Sangue e Hemoderivados do Ministério da Saúde no sentido de fomentar a implantação dessa políticas em todos os estados da União. Alguns estados, como Minas Gerais e Rio de Janeiro, já estão bem avançados, devido ao protagonismo da comunidade médica, do movimento negro e dos gestores sensíveis à causa. $O$ Rio de Janeiro teve a sua política estadual publicada em 2005, porém já vinha trabalhando ações de capacitação de trabalhadores de saúde e estruturando um plano de descentralização da assistência para os municípios desde o início da implantação da fase II do PNTN ${ }^{15}$.

O Pacto pela Saúde - Consolidação do SUS publicado em fevereiro de 2006 é composto de três principais componentes: o Pacto pela Vida, o Pacto em Defesa do SUS e o Pacto de Gestão do SUS ${ }^{16}$. O Pacto pela Vida estabelece seis prioridades sanitárias, sendo que duas delas são muito importantes para a consolidação da Política de Atenção à Doença Falciforme: a promoção da saúde e o fortalecimento da atenção básica.

O cuidado de saúde nos pacientes com AF envolve a participação de uma equipe multidisciplinar integrada. Em muitos casos, os cuidados médicos podem e devem ser realizados por um profissional da atenção primária, com referências periódicas ao especialista para o manejo das complicações mais graves ${ }^{17}$. Em 2006, o Ministério da Saúde elaborou um manual técnico para o acompanhamento de crianças com doença falciforme, voltado especialmente para profissionais da atenção primária em saúde ${ }^{6}$. Esse manual traz recomendações gerais a respeito das consultas de rotina, necessidade de exames complementares e de encaminhamento a especialistas.

Observou-se em um estudo realizado no estado do Amapá que 60\% dos pacientes com AF declararam não receber atendimento adequado pelos profissionais de saúde, esse fato estava relacionado à desinformação dos profissionais sobre a doença. Este acontecimento foi atribuído aos profissionais da área da saúde pois, $80 \%$ dos usuários relataram que estes profissionais desconheciam a doença, tornando uma falha lamentável frente ao fato da anemia falciforme ser uma doença genética descoberta há mais de 100 anos e para a qual se dispõe do diagnóstico neonatal ${ }^{18}$.

A preocupação em disseminar o conhecimento quanto ao atendimento às intercorrências na doença falciforme junto aos profissionais da atenção primária, não deixando este papel somente para os centros especializados, como normalmente acontece, também tem sido apontado pelos autores ${ }^{19}$. Esta informação é muito relevante, visto que em nosso país estes pacientes muitas vezes encontram-se distantes dos centros e poderiam ser melhor atendidos se houvesse profissionais capacitados para tal nas unidades básicas de saúde ${ }^{20}$. 
Por meio de recurso proveniente do Ministério da Saúde, quatro treinamentos foram realizados em Rio Grande do Norte (dois na capital e dois no interior) a fim de capacitar os profissionais da área da saúde para um melhor tratamento dos usuários com doença falciforme e reduzir de taxas de morbidade aumentando assim a qualidade de vida dos mesmos. A eles, foram passadas orientações sobre a doença falciforme a fim de desmistificar a patologia com o objetivo de promover uma melhor compreensão da doença e, assim melhorar a triagem e a conduta durante as situações de agudização da doença na atenção primária ${ }^{21}$.

O Manual de Condutas Básicas na Doença Falciforme ${ }^{22}$ define o protocolo oficial de tratamento e acompanhamento, 0 qual deve estar acessível a todos os pacientes. Apesar de avanços notáveis terem sido realizados na compreensão da base da complexa fisiopatologia da doença falciforme, ainda nenhum medicamento específico foi desenvolvido para seu tratamento, para o qual são utilizados apenas medicamentos par aliviar os sintomas da doença e/ou para tentar evitar complicações mais graves ${ }^{23}$.

O diagnóstico precoce, promovido durante a triagem neonatal no Brasil, propiciou o atendimento e a utilização de medidas educacionais e preventivas como a utilização de antibióticos profiláticos durante a infância, vacinação precoce contra pneumococos e hepatites virais, assim como a utilização de determinados medicamentos tais como o ácido fólico, analgésicos e anti-inflamatórios que auxiliam no bem estar do usuário, na promoção e na recuperação da saúde ${ }^{24,25,26}$. $O$ único tratamento curativo atualmente conhecido é o transplante de medula óssea, porém sua aplicação é restrita por ser considerada de alto risco ao usuário devido à necessidade de doador compatível e a alta taxa de complicações com significativo nível de mortalidade $e^{27,28,22}$.

Até o presente momento, a terapia com hidroxiuréia constitui o avanço mais importante no tratamento dos pacientes com $\mathrm{AF}$, sendo considerada a mais promissora dentre as novas terapias disponíveis. Esta medicação é a única que, efetivamente, tem forte impacto na melhora da qualidade de vida dos mesmos, por reduzir o número de crises vaso-oclusivas, e necessidades de transfusão, número de hospitalizações, além de demonstrar de maneira contundente, redução no número de óbitos decorrentes desta doença quando comparado ao mesmo número em grupo de pacientes sem o uso do medicamento ${ }^{30,31,32}$.

A OMS define política de medicamentos como um conjunto de diretrizes com a finalidade de assegurar para toda a população, uma provisão adequada de medicamentos, de boa qualidade e, com a eficácia proposta ${ }^{33}$. Os medicamentos são produtos utilizados no diagnóstico, na prevenção, na cura ou no alivio de sintomas de doenças. Quando bem administrado, o medicamento é uma ferramenta de promoção, proteção e recuperação da saúde, um aliado na luta contra as morbidades e os sintomas que afligem a humanidade ${ }^{34}$. Portanto, para garantir 0 acesso ao tratamento a todos os usuários acometidos é necessário que haja políticas públicas específicas para esta doença, que garantam um atendimento integral e coordenado, conforme recomendado pela $\mathrm{OMS}^{7}$.

Quanto ao acesso aos medicamentos disponibilizados pelo SUS (dipirona, paracetamol, diclofenaco de potássio, ácido fólico, fenoximetilpenicilina potássica, benzilpenicilinabenzatina, eritromicina), um estudo mostrou que $45 \%$ dos usuários não tem acesso a esses medicamentos essenciais ${ }^{22}$. De acordo com a Portaria do MS (№ 1018/GM de $1^{0}$ de Julho de 2005) ${ }^{35}$ que institui no âmbito do SUS, o Programa Nacional de Atenção Integral as Pessoas com Doença Falciforme e outras Hemoglobinopatias, garante 0 atendimento, 0 apoio diagnóstico, o tratamento, a oferta de imunobiológicos especiais, a disponibilização dos medicamentos específicos aos sinais e sintomas da doença e a aquisição da hidroxiuréia e quelantes de ferro a todas as pessoas com anemia falciforme.

Os medicamentos essenciais são definidos pela $\mathrm{OMS}^{36}$ como aqueles que satisfazem as necessidades prioritárias de saúde da população. Os medicamentos essenciais devem estar disponíveis nos serviços de saúde em todos os momentos e quantidades suficientes. A implantação de programas de triagem neonatal para doença falciforme e a garantia do tratamento feito de maneira adequada, alcançando a adesão completa, 0 atendimento de qualidade e 0 acesso a todos, demonstra a possibilidade de diminuição da morbimortalidade da doença através de uma política pública de atenção à saúde. Portanto, uma atenção integral, descentralizada, multidisciplinar, humanizada, de qualidade e com ênfase no autocuidado pode modificar a história natural da doença falciforme, diminuindo assim as demandas nos hospitais especializados.

\section{Papel do gestor neste seguimento em saúde}

Muito pouco se tem referenciado na literatura a respeito do papel do gestor na atenção à saúde dos pacientes com doença falciforme. Em sua maioria encontram-se revisões de literatura e investigações mais complexas, com escassez de pesquisas que avaliem o papel do gestor na atenção primária à saúde da doença falciforme. Levando em consideração o conceito genérico de administração pública como o conjunto de órgãos do Estado encarregados de exercer, em benefício do bem comum, funções previstas na Constituição e nas leis, pode-se através disto inferir que, o gestor público em saúde também é parte integrante deste processo ${ }^{37}$. 
O elevado potencial de mortalidade pela AF no Brasil resulta da pouca efetividade na implementação de políticas públicas, dado que essa morbidade exige maior atenção do serviço do sistema de saúde ${ }^{38}$. Segundo a OMS, na maioria dos países onde a AF é problema de saúde pública, seu manejo muitas vezes permanece inadequado devido à inexistência de programas nacionais de controle da doença e de práticas sistemáticas de rastreamento populacional ${ }^{7}$.

O papel do gestor neste seguimento em saúde deve-se iniciar mediante um controle de rastreamento da situação da saúde populacional a qual está dirigindo, onde iniciativas devem ser tomadas perante esta classe de profissionais em presença da mobilização dos demais gestores em saúde (regionais e municipais), e formação de facilitadores e de ações educativas na doença falciforme.

Sabe-se que a doença falciforme é uma doença crônica, mas com muitos momentos de agudização, e que, nesses casos, o paciente não só pode como deve ser recebido primeiramente na atenção básica à saúde. Uma maior ênfase por parte dos gestores sobre a doença falciforme poderia ser dada na educação dos profissionais de saúde atuantes nas unidades básicas, pois pode haver dificuldade para trabalhar com estes usuários portadores da doença falciforme. Embora posteriormente o usuário necessite de ambulatórios de atenção secundária, podendo até ser caso de internação, chegando à atenção terciária, todavia tudo deve estar atrelado à atenção primária, a qual deve coordenar o fluxo e acompanhar o usuário.

Apesar de a atenção básica ser responsabilidade dos gestores municipais, o desenvolvimento de ações coordenadas pelos três níveis de governo asseguram condições necessárias para que estas se efetivem com qualidade e de maneira resolutiva. Em busca da qualidade nas ações desenvolvidas, considera-se que os serviços de saúde devem oferecer além do diagnóstico das doenças e seu tratamento, medidas que favoreçam a prevenção de doenças futuras e a promoção do estado de saúde das pessoas e da populações ${ }^{39}$.

Do gestor público em saúde espera-se o direcionamento na atividade e nos serviços públicos à efetividade do bem comum, imparcialidade, neutralidade, transparência, participação e aproximação dos serviços públicos da população, eficácia, desburocratização e busca da qualidade. Neste sentido, o gestor público tem o papel de integrar sua equipe, exigindo eficiência e eficácia na prestação de serviços, agregando novos valores à administração pública em prol de serviços públicos de qualidade ${ }^{40}$.

Para que tudo isso aconteça é primordial que os gestores em saúde estejam devidamente preparados para atuar em todos os ramos da gestão em saúde, dentre eles, na atenção primária. Sabe-se que o gestor despreparado é um dos nós críticos do serviço público de saúde, pois propicia discrepâncias quanto à liderança necessária para conduzir e executar políticas de saúde. O gestor na atenção primária à saúde deve ter uma visão ampla dos atores sociais (usuários e profissionais) que o rodeiam, adaptando-se assim a realidade da saúde local.

Para tanto, é necessário que todo profissional da atenção básica receba treinamento na área e que o paciente tenha acesso adequado, quando necessário, aos níveis secundários e terciários. Um rastreamento neonatal aliado à educação em saúde para os pais reduz de forma importante a morbidade e a mortalidade nos primeiros cinco anos de vida, além de aumentar a qualidade de vida dos pacientes ${ }^{7}$.

Apesar de existirem vários centros especializados de hematologia, a atenção médica habitual a estes pacientes com AF deve ser rotineiramente realizada nas unidades de saúde e no programa saúde da família 5 . Buscar e orientar a formulação de políticas públicas promovendo a equidade em saúde, dispondo de estudos epidemiológicos, prevalência e assim programar e subsidiar um serviço de atendimento para os pacientes com doença falciforme são um dos diferentes papéis que os gestores podem desempenhar e assim fazer a diferença.

Os gestores devem ser profissionais capacitados, com visão ampla voltada ao atendimento das demandas e necessidades de saúde, e ágeis ao tomar decisões para ampliar a resolutividade do sistema. Por ações implementadas pelos gestores, capacitações nos serviços de atenção básica podem ser programadas e realizadas, uma vez que com esta certificação, os profissionais que atendem na unidade de saúde serão habilitados para acompanhar de perto e de forma humanizada os sintomas, os usuários portadores da doença falciforme e seus familiares, podendo assim atender de forma efetiva os casos agudos da doença. Os gestores devem compreender a atenção primária como a porta de entrada ao sistema de saúde e, somente encaminhar para um centro especializadoserealmente for necessário.

De acordo com a Política Nacional Permanente em Saúde ${ }^{3}$ é responsabilidade dos gestores regionais e municipais formularem, promoverem e apoiarem a gestão da educação permanente em saúde, apoiando e fortalecendo a articulação com os municípios, viabilizando a integração de todos os processos de capacitação e desenvolvimento dos trabalhadores da saúde.

A participação da gestão em processos educativos tem possibilitado maior vinculação e responsabilização dos profissionais de saúde e, sobretudo, maior responsabilização em relação ao processo educativo em DF. 0 grande desafio é a integração dos diferentes modos de cuidado do paciente. Mecanismos de referência entre os diferentes níveis de cuidado devem existir para garantir a continuidade dos cuidados, sendo eles definitivamente integrados. 


\section{Considerações Finais}

De forma descentralizada, com ações organizadas e de eficácia comprovada na prevenção com uma assistência multiprofissional com foco no paciente, é que se compõe a integralidade, associada ao modelo do SUS. Aindisponibilidade de indicadores de desempenho e de resultados da política para gestores, profissionais de saúde, pesquisadores e grupos de interesse é o resultado da forma fragmentada como as informações são armazenadas. Portanto, o investimento na implantação de um sistema de informações que possibilite ao mesmo tempo, agilidade, confiabilidade e disponibilidade permitiria a melhoria dos processos e do planejamento pelos gestores, a implementação de mecanismos de monitoramento e de avaliação e o fortalecimento da legitimidade da própria política.

Aos gestores cabe avaliar, promover de oficinas de capacitação e distribuir manuais para sensibilização, como já vem ocorrendo em alguns Estados. Teoricamente as equipes da atenção básica é que devem gerenciar a linha de cuidado do indivíduo, acompanhá-lo, garantir o acesso e organizar os fluxos para outros níveis de assistência, de forma que o vínculo continue com a equipe básica, que é quem deve dar continuidade aos cuidados. Cabe aos gestores também capacitar os profissionais da área da saúde para um melhor tratamento dos pacientes com doença falciforme; redução de taxas de morbidade aumentando assim a qualidade de vida dos mesmos; e assegurar e viabilizar os medicamentos essenciais nos serviços de saúde em todos os momentos e quantidades suficientes, reduzindo a morbimortalidade da doença através de uma coerente política pública de atenção à saúde.

O gestor deve direcionar as atividades e os serviços públicos à efetividade do bem comum, da imparcialidade, da neutralidade, da transparência, da participação e da aproximação dos serviços públicos da população, com eficácia, desburocratização e com a busca da qualidade. Neste sentido, o gestor público tem o papel de integrar sua equipe, exigindo eficiência e eficácia na prestação de serviços, agregando novos valores à administração pública em prol de serviços públicos de qualidade.

Ademais, é papel do Ministério da Saúde, oferecer aos gestores municipais ferramentas de avaliação e de gestão da qualidade das unidades básicas em saúde. Os mesmos devem estar capacitados a administrar, planejar, avaliar, executar, desenvolver e coordenar políticas e programas. Pode-se adquirir por meio de uma maior participação popular, ferramentas que ajudem a descortinar as dificuldades e melhorar o atendimento à saúde. A falta de planejamento de ações pelos gestores e a inadequação dos objetivos aos da comunidade consistem uma lacuna que pode interferir na organização e na resolutividade do serviço.

\section{Referências}

1. Bandeira FM, Leal MC, Souza RR, Furtado VC, Gomes YM, Marques NM. Características de recém-nascidos portadores de hemoglobina $S$ detectados através de triagem em sangue de cordão umbilical. J. pediatr. (Rio J.). 1999; 75(3):167-171.

2. Silla LMR. Doença falciforme: um grave e desconhecido problema de saúde pública no Brasil. J Pediatr (Rio J). 1999;75:145-6.

3. Brasil. Ministério da Saúde. Secretaria de Atenção à Saúde. Departamento de Atenção Especializada. Manual de educação em saúde / Ministério da Saúde, Secretaria de Atenção à Saúde, Departamento de Atenção Especializada. - Brasília: Ministério da Saúde, 2009. v.2 (Série A. Normas e Manuais Técnicos).

4. Naoum PC. Interferentes eritrocitários e ambientais na anemia falciforme. Rev.bras.hematol.hemoter. 2000, 22(1):05-22.

5. Ferraz ST. Acompanhamento clínico de crianças portadoras de anemia falciforme em serviços de atenção primária em saúde. Rev Med Minas Gerais. 2012; 22(3):315-320.

6. Brasil (2006a). Ministério da Saúde. Manual de condutas básicas na doença falciforme. Brasília: Ministério da Saúde.

7. World Health Organization. Sickle-cell anaemia. In: Fifty-Ninth World Health Assembly. Geneva: WHO; 2006.

8. National institutes of health. Division of Blood Disease and Resources. The Management ofSickleCellDisease. Bethesda: NIH; 2002.

9. Araujo DL, Santos GS, Viana NA, Souza SS, Montagner MI. Concepções sintomáticas e sociais da doença falciforme. Participação 23/24, 2013.

10. Barros ASS, Castro ASA, Lira ASL, Souza DS, Carmo JS, Reis LS. Aspectos do enfrentamento da doença por parte de alunos portadores de anemia falciforme da cidade de salvador. Estudos IAT. 2012, 2(2). 
11. Platt OS, Brambilla DJ, Rosse WF, Milner PF, Castro O, Steinberg MH, et al. Mortality in sickle cell disease. Life expectancy and risk factors for early death. N Engl J Med. 1994;330 (23), 1639-1644.

12. Cavalcanti JM, Maio MC. Entre negros e miscigenados: a anemia e o traço falciforme no Brasil nas décadas de 1930 e 1940. Hist. cienc. saude-Manguinhos[online]. 2011, 18 (2), 377-406.

13. Serjeant GR. Screening for sickle cell disease in Brazil. Lancet. 2000; 356, 168-169.

14. Ramalho AS, Magna LA, Paiva-e-Silva RB. A Portaria $n^{0} 822 / 01$ do Ministério da Saúde e as peculiaridades das hemoglobinopatias em saúde pública no Brasil. Cad. Saúde Pública. 2003; 19 (4), 1195-1199.

15. Secretaria Estadual de Saúde (2005). Resolução SES N 2. 786 de 8 de julho de 2005. Define a Política d Atenção Integral à Pessoa com Doença Falciforme do Estado do Rio de Janeiro. SES. Rio de Janeiro, Diário Oficial do Estado do Rio de Janeiro. 16. Brasil (2006c). Portaria 399/GM de 22 de fevereiro de 2006. Divulga o pacto pela saúde 2006 - consolidação do SUS e aprova as diretrizes operacionais do referido pacto. M. Saúde. Brasília, Diário Oficial da República Federativa do Brasil. 17. Lane PA, Buchanan GR, Hutter JJ, Austin RF, Britton HA, Rogers ZR, et al. Sickle cell disease in children and adolescents: diagnosis, guidelines for comprehensive care, and care paths and protocols for management of acute and chronic complications. Sedona, Arizona (USA): SickleCellDiseaseCare Consortium; 2001.

18. Castelo NM, Gomes LF, Nascimento RE, Rodrigues ASN. Anemia falciforme sobre o olhar de pessoas com a doença no amapá. 2012; 2 (2).

19. Kikuchi BA. Assistência de enfermagem na doença falciforme nos serviços de atenção básica. Rev. Bras de Hematol e Hemote, 2007; 29(3):331:338.

20. Rodrigues CCM, Araújo IEM, Melo LL. A família da criança com doença falciforme e a equipe de enfermagem: revisão critica. Rev. Bras de Hematol e Hemote, 2010, 32(3):257-264.

21. Serafim ESS, Soares RM, Oliveira TMX, Soares MJNL. Capacitação de profissionais de saúde para o manejo da dor em adolescentes portadores de doença falciforme na atenção primária. Rio de Janeiro, Adolescência \& Saúde. 2011; 8(4):55-58.

22. Brasil (2006b). Manual de Condutas Básicas na Doença Falciforme, Ministério da Saúde. Secretaria de Atenção à Saúde. Departamento de Atenção Especializada. Série A. Normas e Manuais Técnicos.

23. Nascimento-Jr NM, Melo TRF. Planejamtno, síntese e avaliação farmacológica de novos compostos híbridos para 0 tratamento dos sintomas da anemia falciforme. Rev. Virt de Quim. 2012; 3(6):447-451.

24. Quinn CT, Rogers ZR, Buchanan GR. Survival of children with sickle cell disease. Blood. 2004;103(11):4023-4027.

25. Ministerio da saúde. Secretaria de atenção à saúde. Departamento de atenção especializada. Manual de educação em saúde: linha de cuidado em doença falciforme. 2008; Brasilia. Editora do Ministerio da Saude, v.1.

26. Steinberg MH. Sickle cell anemia, the first molecular disease: overview of molecular etiology, pathophysiology, and therapeutic approaches. Scientific World Journal. 2008; 8:1295-1324.

27. Ferster A. Five years of experience with hydroxyuréa in children and young adults with sickle cell disease. Blood. 2001; 97(11):3628-3632.

28. Buchanan BR. Sickle cell disease. ASH Education program book. 2004; 1:35-47.

29. Schnog J, Duits AJ, Muskiet FA, Tem Cate H, Rojer RA, Brandjes DP. Sicklecelldisease; a general overview. NethJ. Med. 2004; 62(10):364-374.

30. Charache S, Barton, FB, Morre RD, Terrin ML, Steinberg MH, Dover GJ, et al. Hydroxyurea and sickle cell anemia. Clinical utility of a mielosuppressive switching agent. The multicenter study of hydroxyurea in sickle cell anemia. Medicine. 1996; 75(6):300.

31. Loureiro MM, Rozenfeld S. Epidemiologia de internações por doença falciforme no Brasil. Revista de Saude Pública. 2005, 39(6):943-949.

32. Cançado RD, Lobo C, Ângulo IL, Araujo PIC, Jesus JA. Protocolo clinico e diretrizes terapêuticas para uso de hidroxiuréia na doença falciforme. Revista brasileira de hematologia e hemoterapia. 2009, 31(5):361-366,2009.

33. World Health Organization. Identification and control of work-related disease. Geneva: WHO; 1985.

34. Schenckel EP, Rech N, Farias MR, Santos RI, Simões CMO. Assistência farmaceutica. In: Saúde no Brasil Contribuiçoes para a agenda de prioridades de pesquisa. 2004; Brasilia: Ministerio da saúde.

35. Ministério da Saúde. Secretaria de Atenção à Saúde. Departamento de atenção especializada. Protocolos clínicos ediretrizes terapêuticas Volume I. Série A. Normas e Manuais Técnicos, Brasilia. Editora Palotti, 2a edição, 2010.

36. World Health Organization. Relatorio Mundial da Saúde. Saúde mental: nova concepção, nova esperança. Lisboa: WHO; 2002. 37. Silva RO. Teorias da Administração. São Paulo: Pioneira, 2001. 
38. Felix AA, Souza HM, Ribeiro SBF. Aspectos epidemiológicos e sociais da doença falciforme. Ver. Bras. Hemat. Heoter. 2010; 32(3), p.203-208.

39. Pires, VATN. Internações hospitalares por condições sensíveis à atenção ambulatorial: um estudo de caso com gestores e equipes da Estratégia Saúde da Família em uma microrregião de saúde. 2008. 174 f. Dissertação (Mestrado em Enfermagem), Escola de Enfermagem, Universidade Federal de Minas Gerais, Belo Horizonte, 2008.

40. Gomes DFS, Silva JG. Concepção Popular da Função do Gestor Público. VII CONNEPI, 2012.

\section{Lívia Gelain Castilhos}

Endereço para correspondência - Rua: Victorino da Cas, $n^{\circ}$ 600, Casa 106B, Cond. Terra Nova, Bairro: Cerrito, CEP: 97060-491, Santa Maria, RS, Brasil.

E-mail: liviagelain@gmail.com

Lattes: http://lattes.cnpq.br/9457031624793372

Josiane Bizzi Schlemmer Braun - jobizzi@yahoo.com.br

Suzinara Beatriz Soares de Lima - suzibslima@yahoo.com.br

Enviado em 05 de agosto de 2014. Aceito em 13 de dezembro de 2015. 